\title{
Estágio curricular supervisionado e profissionalização docente na percepção de acadêmicos do curso de licenciatura em educação física ${ }^{1}$
}

\author{
Maria Teresa Sudário Rocha* \\ Jairo Antônio da Paixão**
}

\begin{abstract}
Resumo
O presente estudo de natureza qualitativa objetivou identificar e analisar possíveis implicações entre o estágio curricular supervisionado e aspectos da profissionalização docente na ótica de acadêmicos que se encontravam no último ano do curso de licenciatura em Educação Física. A partir dos dados coletados por meio de entrevista semiestruturada, foi possível afirmar que o estágio possibilitou aos acadêmicos perceberem a docência como uma conjunção multifacetária delineada pelas diversas experiências de atuação. Uma profissão que demanda do professor a capacidade de dominar os saberes deparados durante a licenciatura, bem como de colocá-los em prática no cotidiano da escola.
\end{abstract}

Palavras-chave: Estágio supervisionado; Licenciatura; Educação Física; Docência.

\section{Supervised curricular traineeship and teacher professionalization in the perceptions of the undergraduate students in physical education}

\begin{abstract}
This qualitative study identified and analyzed possible implications between the supervised curricular traineeship and aspects of teacher professionalization from the perspective of the undergraduate students in Physical Education who were in the last year of the course. From the data collected through a semistructured interview, it was possible to affirm that the stage made it possible for academics to perceive teaching as a multifaceted conjunction delineated by the different experiences of acting. A profession that demands of the teacher the ability to master the skills encountered during the degree, as well as to put them into practice in the daily life of the school.
\end{abstract}

Keywords: Supervised internship; Graduation; Physical Education; Teaching.

\section{Introdução}

A formação inicial compreende um período no qual os futuros docentes terão, certamente, contato com conhecimentos afins e específicos, além de vivências no ambiente de intervenção profissional que, por sua vez, formarão a base para o desenvolvimento de competências que lhes serão exigidas em uma determinada área de atuação (QUARANTA; PIRES, 2013).

No âmbito das dimensões dos conhecimentos que estruturam as matrizes curriculares dos cursos de licenciatura no país, disciplinas como Metodologia do Ensino, Didática, Prática de Ensino e Estágio Curricular Supervisionado nomeadamente compõem o corpo de saberes pedagógicos diretamente relacionados à prática de intervenção em uma estabelecida área do saber. Dentre elas, as duas últimas passaram a ser instituídas obrigatoriamente, com carga horária definida, a partir da Resolução CNE/CP 02/2002.

Desta forma, as matrizes curriculares passaram a contar com 400 horas de Prática de Ensino e outras 400 horas de Estágio Curricular

*Endereço Eletrônico: maloc1990@gmail.com

***Endereço Eletrônico: jairopaixao2004@yahoo.com.br
Supervisionado nos cursos de licenciatura. Ainda que o texto da referida resolução deixe margem para diferentes interpretações por parte das instituições de ensino superior, tratam-se de disciplinas essenciais na formação do futuro professor no campo de atuação. Observa-se que a Resolução $\mathrm{CNE} / \mathrm{CP}^{\circ}{ }^{\circ} 2$, de $1^{\circ}$ de julho de 2015 , manteve as respectivas cargas horárias para as referidas disciplinas na conformação das licenciaturas do país. Nessa direção, é importante assinalar que o estágio constitui momento ímpar na formação inicial, ao possibilitar ao acadêmico a reflexão sobre a prática pedagógica in loco com seus matizes reais. Sobretudo, esta etapa traduz-se como o momento em que oportuniza ao acadêmico compreender o sistema de ensino, as políticas educacionais, a escola e os alunos com os quais irá desenvolver e construir processos de aprendizagem.

O Estágio curricular supervisionado é entendido por Tardif e Lessard (2005) como uma experiência única e tem um valor de vivência incorporado aos aspectos pessoais e profissionais. Mas os autores acreditam que a experiência não é apenas pessoal, é também social no sentido de definir um grupo com uma ordem de valores e méritos 
atribuídos às ações. Assim, é nesta etapa que o acadêmico do curso de licenciatura é imerso em variados elementos constitutivos de sua profissão, tornando-se importante que ocorra um envolvimento entre o professor da escola, o estudante estagiário e o professor formador da universidade, para que o estágio seja efetivamente significativo (IZA; NETO, 2015), sendo, todavia, necessário que haja uma prática reflexiva (KULCSAR, 1994).

Pesquisas na área da formação de professores coadunam com a ideia da construção da identidade profissional docente no decorrer do curso de formação inicial, que se intensifica durante o período em que o acadêmico se encontra no Estágio Curricular Supervisionado (SILVA, 2010; SAMBUGARI, 2011; PIMENTA; LIMA, 2012). Portanto, é preciso ressaltar que essa etapa, por si só, não possui o potencial de transformar o acadêmico em professor. No entanto, poderá contribuir para que o mesmo tenha a noção da profissão, das emoções, realizações e adversidades de ser professor (SILVA, 2010).

O quadro brevemente apresentado circunscreve o cenário e contexto social em que decorre a maioria dos cursos de formação de professores no país, podendo ser assinalado sobre as experiências e vivências possibilitadas pelo estágio na formação inicial das diferentes áreas das licenciaturas. Nessa perspectiva, é possível incluir às discussões a formação do professor de Educação Física.

Dentre os componentes curriculares que compõem a Educação Básica, indubitavelmente, a Educação Física apresenta especificidades como o ambiente (quadras, pátios e outros espaços) em que se desenvolvem as aulas práticas, o movimento na qualidade de objeto de estudo, e a predileção percebida na grande maioria dos alunos que se encontram no referido nível escolar.

Uma abordagem acerca da identificação do acadêmico com a escola enquanto campo de atuação do professor de Educação Física demanda considerações sobre a crise de identidade epistemológica na qual a área se encontrou mergulhada na década de 1990. Tal crise desestabilizou a formação de seus profissionais, trazendo oscilações na construção de sua identidade pessoal e social, e impedindo-os de conseguirem estruturar as suas experiências de modo a favorecer uma formação mais autônoma (BRACHT, 2007).

Além disso, os cursos de licenciatura em Educação Física se caracterizam por um conjunto de disciplinas pedagógicas desarticuladas das demais e que são desenvolvidas apenas pelas Faculdades de Educação. Existe ainda, uma ênfase dada às disciplinas do campo biomédico. Isto afirma a busca de status acadêmico que, segundo os estudantes, estaria mais agregado ao conhecimento científico presente nas disciplinas de cunho biológico e esportivista (FIGUEIREDO, 2001). Este fato suscita uma série de implicações, como a construção de estereótipos profissionais, deixando de fora importantes aspectos do sentido da profissão docente, uma vez que este ofício tende a ter seus próprios códigos, regras e interesses (DUBAR, 2005).

Atualmente, entende-se o componente curricular "Educação Física" como uma prática de intervenção pedagógica que trata de temas advindos da Cultura Corporal de Movimento. Esta prática contribui no processo de formação dos sujeitos que irão produzir, reproduzir, transformar e partilhar as diversas formas de manifestações corporais que caracterizam essa área do saber (DARIDO, 2005). O próprio nome desta referida área de saber fornece elementos para uma compreensão de seu âmbito cultural, por supor uma educação/influência/intervenção social sobre o físico, um elemento tido como natural do ser humano (DAÓLIO, 2006).

Tendo em vista a concepção de estágio como um momento marcante no processo de "tornar-se professor", acredita-se que investigar esse período da formação inicial seja relevante para conhecer o processo de identificação por parte do acadêmico do curso de Licenciatura em Educação Física com sua futura profissão. Esse reconhecimento se apresenta de extrema valia nas futuras ações desse profissional, que irá atuar nas escolas, no sentido de fazê-lo perceber a importância de refletir sobre sua prática pedagógica em seu trabalho diário. Essa reflexão estimula a melhora da qualidade da ação dos profissionais, ponderando sobre as dificuldades e possibilidades inerentes à futura profissão.

Nesse sentido, o presente estudo identificou e analisou possíveis implicações entre o estágio curricular supervisionado e a profissionalização docente, a partir de percepções dos acadêmicos do Curso de Licenciatura em Educação Física da Universidade Federal de Ouro Preto.

\section{Metodologia}

Considerando os fenômenos estudados, foram adotados os procedimentos de uma pesquisa qualitativa do tipo descritiva (LÜDKE; ANDRÉ, 2013). 
O Curso de Licenciatura em Educação Física escolhido para o desenvolvimento do estudo, tem duração de oito semestres (quatro anos), é noturno e conta com uma carga horária total obrigatória de 3.105 horas.

A dimensão didática pedagógica que permeia a matriz curricular do curso é constituída pelas disciplinas Metodologia do Ensino dos Esportes, Pedagogia da Educação Física, Didática da Educação Física, Educação Física na Educação Básica, Prática de Ensino em Educação Física e Estágio Acadêmico.

A carga horária destinada aos estágios, que se iniciam na segunda metade do curso totaliza 405 horas, dividida em quatro disciplinas que contemplam os seguimentos que compõem a Educação Básica. São elas: EFD 390 - Estágio Supervisionado (90 horas), que possibilita ao estagiário conhecer o ambiente da escola como campo de intervenção profissional, através de observação diagnóstica de aspectos organizacionais e estruturais, além de co-participações; EFD 391 Estágio Supervisionado: Educação Infantil (90 horas), que abrange o ensino da Educação Física na Educação Infantil, mediante o estudo e aplicação dos conteúdos neste período escolar, com suas implicações, limites, avanços e possibilidades na prática pedagógica cotidiana do professor, por intermédio de observações, co-participações e intervenções; EFD 392 - Estágio Supervisionado: Ensino Fundamental (135 horas), que desenvolve o ensino da Educação Física no Ensino Fundamental I e II, abordando diferentes conteúdos e metodologias e, por fim, EFD 393 - Estágio Supervisionado: Ensino Médio (90 horas), em que os estagiários vão conhecer a realidade do último segmento escolar, e suas possibilidades (CEDUFOP, 2008).

Nesse processo, o estagiário é avaliado tanto pela instituição formadora, quanto pela escola, a partir de sua atuação nas atividades de estágio como o cumprimento da carga horária estabelecida, da entrega dos documentos necessários e do desenvolvimento das aulas observadas e ministradas.

De uma maneira geral, tal como se faz presente na matriz curricular, o estágio possibilita ao acadêmico do Curso de Licenciatura em Educação Física, a partir da observação diagnóstica, desenvolver atividades docentes, como planejar, reger e elaborar relatórios com o objetivo de problematizar, refletir e criticar os diferentes cotidianos escolares que vivencia nesta fase da formação inicial (CEDUFOP, 2008).

$\mathrm{Na}$ definição do grupo amostral, foi preciso estabelecer, inicialmente, contato com a coordenação do curso, a fim de levantar informações sobre a situação dos acadêmicos que cursaram as disciplinas de Estágio Supervisionado. Assim, foi assinada uma Carta de Autorização pelo Coordenador do colegiado do curso de Licenciatura em Educação Física da Universidade Federal de Ouro Preto. A partir desse levantamento com a devida autorização, foram considerados como prováveis participantes da pesquisa aqueles acadêmicos que haviam cursado duas disciplinas de Estágio. Essa escolha se deveu ao fato de se tratarem de alunos que possuem uma maior vivência em atividades de docência na escola.

Participaram deste estudo 11 acadêmicos de Licenciatura em Educação Física, sendo cinco homens e seis mulheres, com idade variando entre 21 e 31 anos. Dois desses participantes já eram bacharéis em Educação Física e trabalhavam como instrutores em academias da cidade em que foi desenvolvida a pesquisa. Todos os participantes se encontravam entre o sexto e oitavo períodos letivos do curso.

A seleção dos participantes se deu a partir dos seguintes critérios de inclusão: encontrar-se regularmente matriculado no Curso de Licenciatura em Educação Física, ter assinado o Termo de Consentimento Livre e Esclarecido (TCLE) e ter concluído, no mínimo, duas disciplinas de estágio curricular supervisionado, o que equivale à metade da carga horária total do estágio no curso. Foram considerados como critérios de exclusão os participantes que não se encontravam na situação descrita, a recusa da assinatura do TCLE e o não interesse em participar da investigação.

Para a coleta de dados, foi utilizada uma entrevista semiestruturada que objetiva extrair descrições detalhadas sobre os acontecimentos investigados, aproximando-se mais de um diálogo do que de um levantamento de dados formal (MANZINE, 2004).

$O$ roteiro da entrevista (HAMMER; WILDAVSKY, 1990) foi estruturado a partir dos pressupostos teóricos da literatura especializada, tendo em vista as categorias que versam sobre as descobertas do ser professor no momento do estágio. Primeiramente, foram realizadas perguntas acerca das motivações dos discentes para a escolha do curso de licenciatura em Educação Física. Em seguida, indagou-se sobre o que é a profissão docente. Posteriormente, foram feitos questionamentos detalhados sobre a experiência dos discentes nos estágios realizados, e, por fim, se os estágios acrescentaram algum conhecimento sobre a profissão 
de professor, ou alguma modificação na atuação enquanto futuro docente.

Dentre os procedimentos adotados para a coleta de dados, buscou-se agendar as entrevistas, de acordo com a disponibilidade dos participantes e em locais de escolha dos próprios. As mesmas foram realizadas pelos autores do artigo e gravadas com o emprego de um gravador digital de voz. Todos os encontros foram transcritos na íntegra e analisados.

Para o tratamento dos dados coletados foi empregada a análise de conteúdo (BARDIN, 2011). Nesse processo, conforme propõe a literatura, foram observadas as seguintes etapas: na primeira etapa, foram realizadas leituras e elaboração de indicadores que fundamentem a interpretação. Na segunda etapa, foram codificados os dados a partir de unidades de registro. Por fim, na terceira e última etapa, se fez a categorização, que consistiu na classificação dos elementos segundo suas semelhanças e por diferenciação, com posterior reagrupamento em função de características comuns.

Foi desenvolvida uma análise por categorias temáticas, a fim de averiguar possíveis significados nas respostas dos participantes. O procedimento consistiu basicamente em agrupar os dados considerando suas semelhanças a partir de categorias temáticas. As categorias e subcategorias do presente estudo foram desenvolvidas a partir das respostas das entrevistas (categorização a posteriori), o que evidenciou os dados coletados (BARDIN, 2011; PÊCHEUX, 2014). Essas categorias são apresentadas na seção Resultados e Discussão.

O projeto de pesquisa obteve aprovação do Comitê de Ética em Pesquisa da Universidade Federal de Ouro Preto, Parecer n. 1. 589. 210 em 14 de junho de 2016.

\section{Resultados e Discussão}

A discussão dos resultados obtidos desenvolveu-se através da triangulação entre os dados das entrevistas realizadas com os estagiários do curso de licenciatura em Educação Física, a bibliografia relacionada à temática pesquisada e, ainda, as posições assumidas pelo pesquisador da presente investigação. Desta forma, foi possível uma discussão aprofundada das seguintes categorias de análise: o estágio na instituição e os espaços destinados à sua realização do estágio, que demonstra o contexto do desenvolvimento dos estágios na Instituição escolhida e das escolas; $a$ escolha do curso, que aprofunda as motivações dos alunos participantes da pesquisa; a percepção da profissão docente a partir do estágio e, por fim, influências do estágio na atuação pedagógica do futuro professor de Educação Física, categoria que explana questões da identidade pedagógica dos participantes.

\section{O estágio na instituição e os espaços destinados à realização do mesmo}

Os estágios curriculares supervisionados compõem a estrutura dos cursos de licenciatura. A carga horária destinada a estes, que são iniciados na segunda metade dos cursos, é de 405 horas, e contemplam os seguintes segmentos que compõem a Educação Básica: Educação Infantil, Ensino Fundamental I e II e Ensino Médio. O estagiário é avaliado tanto pela instituição formadora, quanto pela escola campo de estágio, a partir de sua atuação dentro da mesma, do cumprimento da carga horária estabelecida, da entrega dos documentos necessários e do desenvolvimento das aulas observadas e ministradas (Projeto Pedagógico do Curso).

Dentre as escolas de Educação Básica disponíveis para a realização de estágios dos cursos de licenciatura da Universidade Federal de Ouro Preto, destacam-se aquelas pertencentes à rede pública de ensino (municipal, estadual) localizadas nas cidades de Ouro Preto e Mariana, Minas Gerais. Somado a isso, a estrutura em que se organiza o estágio curricular supervisionado do Curso de Licenciatura em Educação Física da referida instituição de ensino permite ao acadêmico definir, no rol dessas escolas, aquela em que fará a intervenção.

Ainda que sejam enfatizadas as escolas da rede pública para a realização dos estágios, é importante assinalar que todas as escolas (municipais, estaduais, federais ou privadas) constituem espaços significativos para a formação do professor. Isso se dá tendo em vista a oportunidade de perceber diferentes realidades que constituem o cotidiano das escolas enquanto espaços de intervenção profissional, e que influirão em sua prática pedagógica (PIMENTA; LIMA, 2012; QUARANTA; PIRES, 2013).

Sob essa ótica, é importante destacar que as especificidades dos cenários e contextos encontrados nas escolas demandam do estagiário, juntamente com o professor da escola e o professor da disciplina estágio, adequações dos planejamentos, procedimentos e estratégias metodológicas no trato dos conteúdos e do público a ser atendido durante este período (GIESTA, 1996). 


\section{A escolha do curso}

Dentre os motivos que influenciam a escolha do candidato pela formação em licenciatura estão as percepções e as expectativas profissionais do sujeito por meio de experiências prévias ao próprio ingresso no curso de formação inicial de professores. Tais experiências acabam por influenciar a identificação com a profissão, o modo como encaram o ensino e seu desenvolvimento profissional (CHONG; LOW, 2009). Sendo assim, dentre os motivos apontados pelos participantes da presente pesquisa, destaca-se o envolvimento com diversas modalidades esportivas, na condição de praticantes e, em alguns casos, de atletas, ao longo da infância e adolescência. Esse dado corrobora com pesquisas na área que identificaram uma correlação entre vivências prévias em determinadas modalidades esportivas e a opção profissional pela graduação em Educação Física (CARDOSO, BATISTA; GRAÇA, 2016).

$O$ ingresso de alunos no Curso de licenciatura em Educação Física que tiveram experiências pregressas como atletas ou tinham envolvimento com o esporte na vertente da competição, leva ao segundo motivo mais citado entre os entrevistados: o não conhecimento da diferença entre os campos de intervenções específicas para as habilitações do bacharelado e da licenciatura na graduação.

Dentre esses resultados, dois participantes ingressaram na instituição na modalidade de transferência de curso, e afirmaram que nas graduações de Licenciatura em Educação Física que se encontravam anteriormente ainda não havia a separação. Como afirma a entrevistada n4:

Na época que eu comecei era junto ainda, era licenciatura e bacharelado, então não foi uma escolha "ah, eu quis ser professora de Educação Física de cara", mas eu queria trabalhar com Educação Física. (n.4)

Esse tipo de abordagem ainda é comum na área da Educação Física, visto que a separação entre as duas habilitações (licenciatura e bacharelado) e as mudanças curriculares são recentes no contexto na Educação Física no país (PIZZANI; BARBOSARINALDI, 2014). Assim, é comum encontrar conflitos de identidade profissional dentro do curso (BERTINI JR; TASSONI, 2013), os quais demonstram lacunas no que se refere à formação inicial do professor de Educação Física, apontando ainda uma fragilidade epistemológica na profissão (VARGAS; MOREIRA, 2012; SILVA E.; SILVA
O.; RIBEIRO, 2013). "Os estudantes, ao optarem pelo curso, não têm uma clara compreensão sobre a licenciatura e [...] estão frequentando um curso que, em última instância, não vai ao encontro de seus interesses, sobretudo, para a atuação profissional" (JUNIOR; MIZUNO; CORRÊA, 2013, p.10).

\section{Percepção da profissão docente a partir do estágio}

Ponderando o fato de que as vivências oportunizadas aos acadêmicos dos cursos de licenciatura no decurso do estágio curricular supervisionado podem resultar em significativas mudanças na forma de se conceber a docência (TARDIF; LESSARD, 2005), foi perguntado se o estágio acrescentou algo sobre a profissão de docente, tendo em vista que a trajetória profissional se configura como processo de construção de sentido para o professor (GADOTTI, 2003).

Dentre os depoimentos obtidos sobre esta temática, destaca-se o relato de uma entrevistada, que chega a condicionar o magistério ao fato de a pessoa ter nascido ou não com "dom" para exercê-lo de forma plena. Antigamente a profissão de professor era enaltecida enquanto dom, pois assim se camuflava a desvalorização do cargo, barateando os custos e fazendo com que as mulheres escolhessem o magistério como profissão, no intuito de estabelecer uma divisão do trabalho de homens e mulheres (BRUSCHINI; AMADO, 1988).

Nesse sentido, é necessário ressaltar a importância do docente se aprimorar e se qualificar enquanto profissional, se comprometendo com a prática educativa. Mas, para tanto, é necessário que os cursos de formação proporcionem discussões que contribuam no entendimento de que ser professor não é algo inato, mas um processo de construção e reconstrução de saberes, práticas e vivências adquiridas (MORAES; OLIVEIRA; MARTINS, 2012).

Uma entrevistada assevera que o estágio trouxe uma percepção de que o professor não está na escola apenas para ordenar os alunos, mas para ser um meio da transmissão de conhecimentos relevantes, o que a deixou com vontade de exercer a profissão:

Eu tô num processo, na verdade assim, eu adorei os estágios que eu fiz e tô adorando os que estou fazendo, e o que acrescentou pra mim é que nós somos a pessoa que vai ali plantar a sementinha nos nossos alunos, para futuras pessoas ativas fisicamente, pensadores, o professor, ele não tá 
ali pra ordenar um conhecimento, mas pra ser um meio de transmissão de conhecimento, uma ponte, o professor é uma ponte, então tem que ser uma ponte pros alunos chegarem lá, então eu vô ali direcionar: "você tem essa opção, você tem essa, e essa", então assim, acho que o professor tem que ser a ponte pra esse conhecimento pros alunos, então somos nós que temos um pouco de conhecimento, eles tem o deles, então tem que ter uma troca, e a gente tem que ser uma ponte pra outros tipos de conhecimento pra eles. (n.1)

Sobre essa percepção da entrevistada, Freire (1996) afirma que o professor deve saber que ensinar não é apenas o ato de transferir conhecimento, mas sim poder criar possibilidades para a sua própria produção/construção. $\mathrm{O}$ autor ainda acrescenta que esse saber precisa ser constantemente vivido pelo professor, envolvendo os alunos.

Um dos entrevistados atenta para a falta de conhecimento da realidade escolar dentro das Universidades, afirmando que, nas aulas, os alunos nem sempre correspondem ao esperado. Nesse caminho, um entrevistado aponta mudanças na percepção da forma de agir dos professores, aprendendo na prática a diferença entre o que é ensinado na Universidade e o que realmente acontece em sala de aula, mostrando para ele a importância de entender melhor os alunos:

A gente faz muito pré-julgamento da criança pelo comportamento dela, a gente esquece que a criança é uma construção, e essa construção, essa formação dela sofre influência de tudo quanto é lado, a gente chega lá e acha que o menino é um capeta, ele é agitado mesmo, mas às vezes ele tem uns comportamentos diferentes dos outros, mas quando a gente vai conhecer a família, a gente descobre por que a criança é daquele jeito, o que ela vive. (...) E outra coisa que me chamou muito a atenção foi a questão de constituição da família. A pergunta elaborada era "como é constituída sua família?", muitas crianças não tem como referência nem o pai nem a mãe, tem como referência a tia ou a avó, isso me fez pensar muito enquanto professor de Educação Física, isso faz a gente conhecer como é o meu aluno na escola, colabora pra que eu entenda como é o comportamento dele, (...) Pra mim, o importante, da Educação Física, o que eu levo pra minha vida todo dia, é esse comportamento; hoje eu consigo olhar pra uma criança e ver e falar assim "aquele menino é muito atentado" e "aquela menina é muito quietinha", mas por que que ele é tão atentado assim? Por que ele se comporta assim? Por que que ele agride os coleguinhas? E a menina é tão calada, por que ela é tão calada? (n.3)
Alguns autores como Freire (1996), Falteri (1998) e Gadotti (2003) consideram que a percepção da realidade do aluno exerce um papel importante na profissão de professor, pois auxilia no desenvolvimento de um trabalho reflexivo que atenda às necessidades desses alunos em diferentes contextos sociais e culturais. Relacionada a esta questão, uma entrevistada fala sobre a arte de ensinar e criar pessoas, que chama atenção sobre o papel de educador do professor:

Ó, eu vejo muito a profissão de professor como a profissão de educador, porque educar é diferente de ser professor, entende? Porque quando você fala "o educador", ele tem uma função... é... muito mais ligada a formar o indivíduo assim, de forma integral, que é o que eu acredito, sabe? Tanto em aspectos, no nosso caso, (...) físico, cognitivos, enfim, todos... Eu entendo essa, a função do professor como sendo essa de ajudar, na verdade auxiliar na construção do ser humano que você tá trabalhando, entendeu? É mais um auxiliador, ele não sabe tudo (...). (n.11)

Em alemão, educar significa cuidar e acolher e, em nossa sociedade, há dificuldade em educar, pela falta de cuidado e acolhimento. Logo, o ato de educar é muito complexo, e o êxito do ensino depende da capacidade do educador de criar espaços de aprendizagem: os educadores não só transformam a informação em conhecimento, mas também formam pessoas (GADOTTI, 2003). De acordo com o autor, educar é também aproximar o ser humano do que a humanidade produziu, não tornando possível pensar apenas em conhecimentos técnicos.

Uma entrevistada chamou atenção para a percepção de seus próprios limites enquanto futura professora da Educação Básica. Essa percepção advém do fato de que sua mãe era professora e, no contato com a escola, notou que as situações se apresentam de forma inteiramente diferentes do que ela imaginava. Então, refletiu sobre as vivências de sua mãe e as suas próprias, desenvolvendo determinada relação com os alunos e compreendendo que deveria ter uma atuação mais segura, com maior firmeza na escola.

Sobre ter um familiar docente e ter vivenciado a escola de diferentes formas, Oliari et al. (2012) acrescenta que a construção da identidade do professor deve ser considerada a partir das experiências a partir de toda sua história de vida, que carrega consigo uma carga de experiência familiar, social, cultural, religiosa, econômica e a sua inserção 
na carreira docente. Pois há expectativas acerca da docência, oriundas de processos de socialização antecipada (DUBAR, 2005), e esses valores e significados podem ser (re)construídos em diferentes momentos da formação sob novas relações estabelecidas (PIZANI; BARBOSA-RINALDI, 2014).

Como foi afirmado anteriormente, com as vivências práticas nos estágios, os padrões de comportamento reconhecidos pelos acadêmicos com relação à profissão docente tendem à sua intensificação e/ou ressignificação. Assim, o estágio curricular supervisionado é considerado um momento em que é passível de ocorrer a (re)construção da identidade profissional.

Nessa categoria, uma das entrevistadas menciona possíveis experiências prévias em contato com diferentes professores e escolas ao longo da trajetória. De acordo com ela, a profissão docente abarca diferentes características, provenientes de diferentes experiências. De acordo com Pimenta (2012), a identidade profissional do professor parte dos saberes experienciais, assim como os profissionais, curriculares e disciplinares (TARDIF, 2011).

Acho que é um conjunto de coisas, eu acho que conta um pouco da sua experiência, do que você já viveu, o que você está aprendendo e o que o aluno tem pra te oferecer, então você junto aquilo lá e transforma em uma forma de conhecimento pra ele absorver aquilo, eu acho que é isso, uma junção de tudo. (n.1)

Ainda nesse sentido, de transformar os saberes adquiridos em saberes escolares, dois participantes citam a capacidade de saber o que foi aprendido durante a sua licenciatura e colocar em prática quando formado. Essa "transformação" de conhecimento para o aprendizado do aluno é amplamente discutida por Tardif (2011), ao afirmar que os saberes sociais são transformados em escolares através dos saberes disciplinares, curriculares, pedagógicos, experienciais e dos saberes oriundos das ciências da educação. Então, o autor, em suma, resume que o professor ideal deve conhecer sua matéria, sua disciplina e seu programa, possuindo conhecimentos sobre as ciências da educação e a pedagogia, desenvolvendo um saber prático baseado em sua experiência cotidiana com os alunos.

Uma das entrevistadas relaciona a profissão docente a algo que remete de maneira concomitante a prazer e sofrimento, posto que, além dos vários fatores que desvalorizam a profissão docente (CUNHA, 2012), a Educação Física ainda enfrenta um grande desprestígio dentro da escola, mesmo dos professores de outras áreas do conhecimento. Portanto, é necessário compreender que, mesmo com o amor e o prazer à profissão, as dificuldades e desafios são vistos como reguladores da ação docente.

A entrevistada n.11 considerava a Educação Física enquanto uma área de conhecimento reflexiva, com diferentes conteúdos e abordagens pedagógicas, $\mathrm{e}$, quando foi para a realidade, a vivenciou enquanto uma aula de lazer, como se fosse recreação, o que trouxe frustração no que se refere à profissão:

Ah, o que... a visão que eu ti... talvez eu fiquei um
pouco assim mas ah, isso sabe o que acontece?
Porque tipo assim... você mentaliza alguma coisa,
mas talvez que você mentaliza aquilo pra você
entendeu? Ou seja, eu penso numa Educação
Física escolar que é uma Educação Física escolar
que não é tipo Lazer, que não é outra coisa. É uma
Educação Física, tipo, é aula, uma disciplina
como qualquer outra. Aí quando você chega lá e
você não vê isso você fica um pouco frustrado,
sabe? Mas querendo ou não, isso não deixou de
me fazer pensar que eu quero uma Educação
Física, entendeu? Por mais que tenha um
negativo, eu quero ser o diferencial, entendeu?
(n.11)

Ao final, a entrevistada afirma que quer ser o diferencial dentro da escola, assinalando que a paixão pela docência promove a vontade de se ser um professor empenhado em transformar a sociedade através da formação de alunos capazes de pensar criticamente (SANCHONETE; MOLINA NETO, 2010).

\section{Influências do estágio na atuação pedagógica do futuro professor de Educação Física}

Em sua maioria, os participantes da pesquisa afirmaram que o estágio acrescentou no que se refere à atuação pedagógica dos mesmos. Essa porcentagem corrobora com estudos na área que afirmam que esta etapa colabora para que o futuro professor possa estar preparado para conduzir ações docentes na escola enquanto espaço de intervenção numa realidade social concreta (MARTINY; SILVA, 2011; ZOTOVICI et al. 2013; MOLETTA, et al. 2013; IZA; NETO, 2015).

Dentre os deslocamentos das práticas pedagógicas explicitadas pelos estagiários, foram citadas diferentes transformações nos momentos no 
estágio, nas relações com os professores e alunos e nos estudos feitos em sala de aula. Além disso, dois dos entrevistados relataram que o estágio possibilitou a percepção de que é preciso planejar e organizar suas intervenções educativas, por exemplo, criar um plano de atividades para os alunos.

Um participante toca em um ponto importante que é, além de desenvolver planejamentos, seguir as especificações da instituição em que trabalha, a fim de desenvolver um trabalho bem sistematizado e organizado para ensinar os conteúdos, que são de extrema importância. Ele demonstra a importância que percebeu de seguir o currículo da escola, adequar à faixa etária dos alunos e desenvolver todos os conteúdos da Educação Física, não apenas os esportes de forma engessada.

Uma das entrevistadas acreditava que o estágio não passava de burocracia, mas aprendeu imensamente nesta área de organização, também chamando atenção para a percepção de que é preciso buscar alternativas para atividades dentro do contexto escolar. Autores afirmam que existe a percepção de que os cursos de formação de professores desenvolvem currículos distanciados da realidade das escolas, desenvolvidos com estágios numa perspectiva apenas burocrática, que não dá conta das contradições presentes na prática educativa, e isso não tem contribuído para a construção da identidade docente (PIMENTA, 2010).

Próxima a essa discussão, uma participante afirmou que o estágio a deixou mais criativa na atuação pedagógica:

Sim... deixa a gente mais criativo... porque (...) se você não tem carta na manga, você vai chegar lá e vai ficar perdido e os professores vão notar, a direção vai notar que você não tem dom, acho que mais criatividade, mais postura, acho que isso. (n.2)

A discussão dessa entrevistada se baseia no fato de que nem sempre o planejamento vai dar conta da realidade da turma de alunos em que o professor está ministrando sua aula. Sendo assim, ressalta-se a importância de que, sempre que necessário, sejam buscadas adequações dos planejamentos, formas de lidar com públicos que demandam necessidades e procedimentos diferenciados (MAIA; SOARES; VICTORIA, 2009). Mas, para isso, é importante que haja antes algum planejamento a ser trabalhado.

Um entrevistado afirmou ter se tornado mais flexível com os interesses dos alunos, pois é preciso desenvolver certos conteúdos, mas eles só querem as mesmas aulas:

(...) hoje nas aulas de Educação Física os alunos estão acostumados com certas coisas, a gente não pode chegar batendo de frente com eles se não a gente não vai conseguir trabalhar com eles, vamos supor, a realidade da escola, tão acostumado com futsal, você vai chegar e vai trazer basquete, um vôlei, não é isso. A escola no ensino médio que eu tô fazendo hoje, os alunos só quer futsal e mais nada, só futsal, as meninas um pouco queimadinha, mas fica ali dez minutinhos e já tão cansada, entendeu? Então é só futsal, futsal, futsal. Então é difícil tirar isso deles, é difícil, você vai chegar e impor isso, os alunos vão simplesmente sentar e falar "Eu não vou fazer!" e pronto, então é tentar contornar eles aos poucos, "Quer jogar futsal, então, beleza! Vamos fazer dez minutos de outra modalidade." outro dia, uma vez por semana vamos trabalhar outra modalidade, tentar diversificar um pouco, mas sempre conversando com eles ali pra melhorar a situação. (n.9)

A flexibilização da prática dos professores é citada por Libâneo (1994), que afirma que o ambiente escolar está sempre se reorganizando, e, portanto, é necessário haver coerência entre os objetivos gerais, objetivos específicos, conteúdos, métodos e avaliação, adequando-se sempre o que será desenvolvido com os alunos à realidade específica. Além da flexibilidade ao tratar os conteúdos da Educação Física com os alunos, uma entrevistada afirma que aprendeu a importância de progressões pedagógicas com os conteúdos a serem trabalhados nas diferentes aulas a serem ministradas.

Uma sequência pedagógica de conteúdos é extremamente importante nas aulas de Educação Física, a fim de garantir o aprendizado das diferentes dimensões da cultura corporal, envolvendo o conhecimento sobre o corpo, esportes, jogos, lutas, ginásticas, atividades rítmicas e expressivas (BRASIL, 1998). Mas, ainda, é importante discutir nessa entrevista sobre a palavra "aplicar". A palavra aplicar remete a uma colagem, uma sobreposição, como se o conhecimento fosse apenas depositado aos alunos. Mas, em uma prática pedagógica reflexiva, as aulas são planejadas e moldadas a fim de corresponderem a uma realidade e contexto específicos, onde os alunos são seres produtores de sentidos que não responderão da mesma forma a determinados conteúdos a serem desenvolvidos em aula.

Essa é uma questão importante, pois, na 
matriz curricular do próprio curso de Licenciatura em Educação Física da referida IES, no que se refere aos estágios, é usada a palavra "aplicar" em suas ementas, reduzindo os significados da própria prática docente enquanto crítica e reflexiva.

Um resultado trouxe um pensamento sobre construção da identidade profissional do professor de Educação Física a partir do contato e trabalho com os professores das escolas, pois o entrevistado afirma que, em cada estágio realizado por ele, ele acumulou alguma característica de cada professor, adicionando a isso, sua personalidade.

Sobre essa observação Dubar (2005) afirma que a identidade é construída e reconstruída a partir de sucessivas socializações. Portanto, se observa que a identificação ou não com certas atribuições que são do outro é o centro da formação identitária. $\mathrm{O}$ autor ainda especifica que, para a formação da identidade, há um cruzamento de processos relacionais e processos biográficos: no primeiro, o sujeito é analisado pelo outro dentro dos contextos onde estão inseridos; já os processos biográficos tratam da própria história, projetos e habilidades do sujeito. $\mathrm{Ou}$ seja, a formação identitária passa pelo sujeito e pelas socializações as quais se submete.

Uma entrevistada afirmou que o estágio acrescentou muito em sua identidade pedagógica, pois afirma que a didática ensinada nas universidades não dá conta da realidade, novamente nos trazendo para a discussão da distância entre a teoria e a prática. De acordo com ela, na escola o professor se depara com turmas de alunos completamente diferentes e com peculiaridades que nem sempre são estudadas na formação inicial.

Nesse sentido, da relação entre a Universidade e a Escola, uma entrevistada fez uma reflexão sobre as abordagens pedagógicas ensinadas em sala de aula na graduação e o momento de estágio enquanto ocasião de se pensar efetivamente sobre essas práticas. Como afirma:

(...) se você vai pra, pro ambiente da escola, não sei se você vai dar uma aula teórica ou uma aula prática, cê tem que tá preparado praquilo, e querendo ou não, você, no decorrer da graduação, das leituras que cê vai fazendo, das aulas, cê vai criando um um... modelo (...) cê vai se formando, vai aprendendo e você também vai aprendendo como você quer ser, entendeu? Então tipo assim, você vai aqui tem as pedagogias, então você se apropria de alguma que cê acha que você considera a melhor pra poder passar né, uma forma mais fácil... aí, querendo ou não, o estágio te faz é se ligar nisso... você não pode chegar lá e só chegar e tipo assim: vamo fazer isso aqui... cê tem que ter embasamento, entendeu? Tem que ter uma ordem, e tem coisas que vão fazer sentido pra quem tá... pro aluno, no caso. Então, é no estágio que você tem essa consciência... e quando você não tá na prática, você não tem isso. Você só vem aqui (em sala) e escuta o que o professor fala, pensa um pouquinho, mas você não reflete realmente aqui. (n.11)

A fala da entrevistada corrobora com o que Pimenta e Lima (2012) comentam sobre o estágio enquanto momento de integrar o processo de formação do aluno, de modo a considerar o campo de atuação como objeto de interpretação crítica, a partir de nexos com as disciplinas do curso. Neste quesito, as autoras consideram que o estágio será o momento em que o aluno de graduação vai ressignificar e refletir sobre as disciplinas do curso, onde são ensinadas diferentes concepções pedagógicas, didáticas e formas de ser e agir.

A Educação Infantil foi citada por uma entrevistada enquanto lugar onde mais ocorreram mudanças em sua prática pedagógica. Ela citou a ajuda do professor supervisor na elaboração de seus planos de aula e sua adequação à faixa etária dos alunos:

Quando fiz meus primeiros planos de intervenção, eu fiz e logo depois eu fui conversar com o professor, então assim, ele já me deu vários toques do que fazer e o que não fazer, porque, por exemplo, no colégio tem maternal, maternal 2, então são meninos de 2, 3 anos, aí eu fiz o primeiro plano bem bobinho, porque eu achei que eles não fossem dar conta, e depois conversando com o professor ele falou assim: você pode dar o que quiser, subir na parede, descer, que eles vão dar conta de fazer... então, nesse intuito, acrescentou muito mais o infantil, porque teve esse diálogo maior com o professor e tal. (n.8)

A partir da fala da entrevistada, é possível perceber que o estagiário pode apreender elementos constitutivos de sua profissão, sendo importante que ocorra um envolvimento entre o professor da escola e o estudante estagiário, para que o estágio seja efetivamente significativo (IZA; NETO, 2015). A interação professor-aluno é destacada como aspecto fundamental do funcionamento da situação didáticopedagógica para a assimilação dos conhecimentos, hábitos e habilidades do professor de Educação Física escolar, pois, como comenta Dubar (2005), diferentes socializações são essenciais para uma formação identitária. 
Uma entrevistada comentou o aprendizado sobre o comando de voz, no sentido de conseguir chamar a atenção dos alunos para as atividades sem gritar. De acordo com ela:

Sim, principalmente na área de comando de voz. De chamar atenção, de puxar os alunos... porque eu percebia que o seguinte: quando abre... quando grita muito, eles não te ouvem, então cê, eu tinha que arranjar estratégias, principalmente no ensino médio, tinha que arranjar estratégias pra chamar atenção deles de forma que eu não ficasse gritando pra eu não acabar a voz e que eles prestassem atenção.. então assim, me ensinou a como chamar atenção dos alunos. (n.10)

Reconhece-se que a atividade diária do professor de Educação Física é dificultada se a voz é acometida por algum problema. Então é importante que, em sua formação, o graduando aprenda diferentes formas de utilizar os estímulos orais no sentido de ministrar suas aulas sem forçar demais as cordas vocais, visto que a comunicação oral influi nos resultados dos processos de ensinoaprendizagem na escola (FIGUEIREDO; LEITE, 2007).

\section{Conclusão}

Diante das constatações e dos resultados obtidos na investigação, é possível afirmar que a análise, realizada a partir das percepções de acadêmicos de Licenciatura em Educação Física da Universidade Federal de Ouro Preto, das implicações existentes entre o estágio curricular supervisionado e aspectos da profissionalização docente, resultou em informações que despertam para uma reflexão sistemática sobre a temática no campo da Educação e da Educação Física.

A partir dos resultados, fez-se um diagnóstico inicial das escolas disponíveis para a realização de estágios dos cursos de licenciatura, em que se destacam as pertencentes à rede pública de ensino (municipal, estadual), ressaltando-se a importância das vivências pelo futuro professor de diferentes realidades e contextos em se inserem as escolas de Educação Básica em nosso país.

Dentre as motivações pela escolha do curso, os resultados revelaram que, em sua maioria, a opção pelo curso de licenciatura em Educação Física se deu pelo envolvimento dos ingressos em modalidades esportivas ao longo da infância e adolescência.

Chamou atenção o fato de o grupo amostral ter sido constituído por acadêmicos que se encontravam na segunda metade do curso, mas, ainda assim, não se evidenciou esclarecimento por parte dos mesmos da especificidade entre os campos de intervenções das habilitações do bacharelado e da licenciatura na formação inicial.

No que concerne às atribuições e competências específicas ligadas aos respectivos campos de intervenções, esse resultado mostra que as discussões que envolvem os contextos e cenários sociais em que decorrem a formação e atuação do profissional em Educação Física em espaços de intervenção distintos ainda merecem destaque e preocupação no âmbito acadêmico brasileiro.

Quando abordadas as expectativas dos participantes sobre os momentos de estágio que perpassam as experiências vivenciadas nessa etapa da formação inicial, o estudo revelou expectativas positivas e negativas com relação a este período despendido nas escolas. Em alguns casos, as experiências foram marcadas positivamente pelas boas práticas dos professores supervisores.

Um resultado interessante foi o de um entrevistado, que trazia consigo expectativas de aprender a ser professor, corroborando com a ideia do presente estudo, em que o estágio colabora na construção da identidade docente, por possibilitar a reflexão e a análise crítica das diversas representações sociais.

A maioria dos participantes afirmou que os estágios realizados até o momento em que se deram as entrevistas contribuíram para sua ressignificação da profissão docente, trazendo, por exemplo, a percepção de um entrevistado de que o professor trabalha enquanto um meio de transmissão de conhecimentos relevantes, atraindo a vontade de exercer a profissão e ressaltando o papel de educador do docente.

A profissão docente foi explicitada em outro momento, enquanto uma conexão de várias características, oriundas de diferentes experiências, e da necessidade adicional do professor ter capacidade de saber o que foi aprendido durante a licenciatura e colocar em prática após a formação.

Os resultados obtidos no presente estudo permitem afirmar que o estágio colaborou para a identificação e ressignificação da profissão docente na área da Educação Física de parte dos entrevistados, por gerar uma aproximação real com o ambiente escolar e do referido componente curricular na escola.

Contudo, percebe-se a necessidade de uma maior reflexão sobre o momento de estágio, pois, as dificuldades encontradas nas aulas de Educação 
Física nas escolas e a forma como é desenvolvida esta etapa na instituição podem limitar o potencial transformador dessa fase da formação. Por conseguinte, são indicados mais estudos sobre o estágio enquanto ponto ímpar de (re)construção identitária da profissão de professor, mediante análises das aulas ministradas pelos graduandos em Licenciatura em Educação Física, com vistas ao aprofundamento desses aspectos.

O desenvolvimento da presente pesquisa possibilitou, aos pesquisadores, adentrar na ambiência do Estágio Curricular Supervisionado em que emergiram fragilidades clássicas, como a dissonância entre teoria e prática. Mas, ao mesmo tempo, confirmou-se o estágio como um momento de grande relevância no processo identitário de tornarse professor, através de percepções advindas das vivências nas escolas pelos acadêmicos no decorrer da formação inicial.

\section{Nota}

1 Artigo resultante de uma investigação desenvolvida como trabalho de dissertação de mestrado em Educação do Programa de PósGraduação em Educação da Universidade Federal de Ouro Preto, MG. A referida investigação contou com o financiamento da Coordenação de Aperfeiçoamento de Pessoal de Nível Superior (CAPES) no período de 2015 a 2017.

\section{Referências}

BARDIN, L. Análise de Conteúdo. $5^{\mathrm{a}}$ ed. Lisboa: Edições 70, 2011.

BERTINI JR, N.; TASSONI, E. C. M. A Educação Física, o docente e a escola: concepções e práticas pedagógicas. Revista Brasileira de Educação Física e Esporte, São Paulo; v.27, n.3, p.467-83. Jul-Set. 2013.

BRACHT, V. Educação física \& ciência: cenas de um casamento (in)feliz. 3. a ed. Ijuí, RS: Ed. Unijuí, 2007.

BRASIL. MEC. CNE. 1998. Resolução CEB 02/98. Institui as Diretrizes Curriculares Nacionais para o Ensino Fundamental. Brasília: Câmara de Educação Básica do Conselho Nacional de Educação, 07/04/1998.
BRUSCHINI, C.; AMADO, Estudos sobre mulher e educação: algumas questões sobre o magistério. Cadernos de pesquisa, São Paulo: Cortez/Fundação Carlos Chagas, 1988.

CARDOSO, I.; BATISTA, P.; GRAÇA, A. A identidade do professor de Educação Física: Um processo simultaneamente biográfico e relacional. Movimento, Porto Alegre, v.22, n.2, 523-38, abr./jun. de 2016.

CEDUFOP - Centro Desportivo da Universidade Federal de Ouro Preto. Projeto Pedagógico dos Cursos de Licenciatura e Bacharelado Em Educação Física, 2008.

CHONG, S.; LOW, E. L. Why I want to teach and how I feel about teaching-formation of teacher identity from pre-service to the beginning teacher phase. Educational Research for Policy and Practice, Singapore, n.8, p.59-72, 2009.

CUNHA, M. I. O bom professor e sua prática. 24. ${ }^{\text {a }}$ ed. Campinas, SP: Papirus, 2012.

DAÓLIO, J. Cultura: educação física e futebol. 3. ${ }^{\text {a }}$ ed. Campinas: Editora da UNICAMP; 2006.

DARIDO, S. C. Educação Física na Escola: implicaçõos para a prática pedagógica. $1^{\mathrm{a}}$ ed. Rio de Janeiro: Guanabara Koogan, 2005.

DUBAR, C. A socialização: construção das identidades sociais e profissionais. $3^{\mathrm{a}}$ ed. SP: Martins Fontes, 2005.

FALTERI, P. Interculturalismo e culturas no Plural. In: FLEURI, R. M. (org.). Intercultura e Movimentos Sociais. Florianópolis: Mover, NUP, 1998, p. 33-44.

FIGUEIREDO, Z. C. C. A formação docente, currículo e saber. In: CAPARROZ, F. E. Educação Física escolar: política, investigação e intervenção, v. 1. Vitória: Proteoria, 2001, p. 115-139.

FIGUEIREDO, A. M; LEITE, D. R. Comunicação oral e interação com os alunos: o uso da voz pelos professores em sala de aula. $1^{a}$ ed. Ouro Preto: Editora UFOP, 2007.

FREIRE, P. Pedagogia da autonomia: saberes necessários à prática educativa, $34^{\mathrm{a}} \mathrm{ed}$. São Paulo: Paz e Terra, 1996. 
GADOTTI, M. Boniteza de um Sonho: ensinar e aprender com sentido. $1^{a}$ ed. Novo Hamburgo: FEEVALE, 2003.

GIESTA, N.C. Tomada de decisões pedagógicas no cotidiano escolar. In: Encontro Nacional de Didática e Prática de Ensino, VIII, 1996, Florianópolis. Anais - Volume 1, Florianópolis: UFSC/UDESC, 1996. p.132-3.

HAMMER, D.; WILDAVSKY, A. La entrevista semiestructurada de final abierto: aproximación a una guía operativa. Historia y fuente oral.

Barcelona: Universidade de Barcelona, n. 4, p. 2361. 1990.

IZA, D. F. V.; NETO, S. S. Os desafios do estágio curricular supervisionado em Educação Física na parceria entre universidade e escola. Movimento, Porto Alegre, v.21, n.1, p.111-24, jan./mar. de 2015.

JUNIOR, L. G.; MIZUNO, F. R.; CORRÊA, D. A. Motivações para a (falta de) escolha pela Licenciatura em Educação Física. Educação, Batatais, v.3, n.1, p.9-30, junho, 2013.

KULCSAR, R. O estágio supervisionado como atividade integradora. In: PICONEZ, S. C. B. (Coord.). A prática de ensino e o estágio supervisionado. São Paulo: Papirus, 1994, p.63-74.

LIBÂNEO, J. C. Didática. $2^{\mathrm{a}}$ ed. São Paulo: Cortez Editora, 1994.

LÜDKE, M.; ANDRÉ. M. E. D. A. Pesquisa em educação: abordagens qualitativas. $2^{\mathrm{a}}$ Ed. São Paulo: EPU, 2013.

MAIA, R. C. C.; SOARES, A. B.; VICTORIA, M. S. Um estudo com professores da educação infantil e do ensino fundamental sobre suas habilidades sociais e inteligência geral. Estudos e Pesquisas em Psicologia, Rio de Janeiro. Ano 9, n.2, p.464-79, 2009. Disponível em:

http://www.revispsi.uerj.br/v9n2/artigos/pdf/v9n2a1 3.pdf Acesso em: 16 nov.2016.

MANZINE, E. J. Entrevista Semi-estruturada: Análise de objetivos e de roteiros. In: Seminário Internacional Sobre Pesquisa e Estudos Quantitativos, 2, A pesquisa quantitativa em debate. Bauru, 2004. Disponível em: https://www.marilia.unesp.br/Home/Instituicao/Doc
entes/EduardoManzini/Manzini_2004_entrevista_se mi-estruturada.pdf Acesso em: 21 jan.2016.

MARTINY, L. E.; SILVA, P. N. S. O que eu transformaria? Muita coisa!: os saberes e os não saberes docentes presentes no estágio supervisionado em educação física. Revista da Educação Física/UEM, Maringá, v.22, n.4, p.56981, 4. trim. 2011.

MOLETTA, A. F. et. al. Momentos marcantes do estágio curricular supervisionado na formação de professores de Educação Física. Pensar a Prática, Goiânia, v.16, n.3, p.715-30, jul./set. 2013.

MORAES, D. A. F.; OLIVEIRA, C. C.; MARTINS, N. Futuros professores: representações discentes da docência. In: ANPED SUL 2012, 2012, Caxias do Sul. Anais... IX Anped Sul - Seminário de Pesquisa em Educação da Região Sul, 2012.

OLIARI, F. A. S. et al. Refletindo sobre a identidade e a formação do professor da educação superior. Educação em Foco, Amparo, v. 5, p.1-13, 2012.

PÊCHEUX, M. Análise automática do discurso (AAD-69). In: GADET, F., HAK, T., (Org.). Por uma análise automática do discurso: uma introdução à obra de Michel Pêcheux. 5a ed. Campinas: (SP): Ed Unicamp, 2014.

PIMENTA, S. G. Formação de professores: identidade e saberes da docência. In: PIMENTA, S. G. Saberes pedagógicos e atividade docente. 5. $^{\mathrm{a}} \mathrm{ed}$. São Paulo: Cortez, 2012.

. O Estágio na Formação de Professores: unidade teoria e prática? 4. ${ }^{\text {a }}$ d. São Paulo: Cortez, 2010.

PIMENTA. S. G.; LIMA, M. S. N. Estágio e Docência. $7^{\mathrm{a}}$ ed. São Paulo: Cortez, 2012.

PIZANI, J.; BARBOSA-RINALDI, I. P. Identidade dos cursos de licenciatura e bacharelado em Educação Física no Paraná: uma análise das áreas do conhecimento. Revista Brasileira Educação Física e Esporte, São Paulo, v.28, n.4, p.671-82, out./dez. 2014.

QUARANTA, A. M.; PIRES, G. L. Histórias de vida e experiências docentes no estágio 
supervisionado de licenciandos em Educação Física - modalidade EAD. Movimento, Porto Alegre, v.19, n.2, p.185-205. Porto Alegre, 2013.

SAMBUGARI, M. R. N. O estágio como espaço de investigação da socialização do exercício docente. Nuances: estudos sobre Educação, Presidente Prudente, SP, v.20, n.21, p.99-116, set./dez. 2011.

SANCHONETE, M. U.; MOLINA NETO, V. Práticas Pedagógicas: Entre a reprodução e a reflexão Rev. Bras. Cienc. Esporte, Campinas, v.31, n.3, p.59-78, maio. 2010.

SILVA, C. S. C. De estudante a profissional: A transição de papéis na passagem da universidade ao mercado de trabalho. 2010. 123f. (Dissertação de mestrado não publicada). Universidade Federal do Rio Grande do Sul, Porto Alegre, RS, 2010.

SILVA, E. A.; SILVA, O. O.; RIBEIRO, C. B. Formação pedagógica do professor de Educação Física: reflexões iniciais acerca das abordagens críticas. EFDeportes.com, Revista Digital. Buenos Aires - Ano 18 - No 180 - Maio de 2013.

TARDIF, M. Saberes docentes e formação profissional. 16. ${ }^{\mathrm{a}}$ ed. Petrópolis: Vozes, 2011.

TARDIF, M.; LESSARD, C. Trabalho Docente: elementos para uma teoria da docência como profissão de interações humanas. $1^{\mathrm{a}}$ ed. Petrópolis, Rio de Janeiro: Vozes, 2005.

VARGAS, C. P.; MOREIRA, A. F. B. A crise epistemológica na educação física: implicações no trabalho docente. Cadernos de Pesquisa, São Paulo, v.42, n.146, p.408-27 maio/ago. 2012.

ZOTOVICI, S. A. et al. Reflexões sobre o estágio supervisionado no curso de licenciatura em Educação Física: entre a teoria e a prática. Pensar a Prática, Goiânia, v.16, n.2, p.568-82, abr./jun. 2013.

\section{Sobre os autores}

Maria Teresa Sudário Rocha é professora do Curso de Licenciatura em Educação Física da Faculdade Presidente Antônio Carlos (UNIPAC) Conselheiro Lafaiete, MG. Licenciada em Educação Física pela Universidade Federal de Ouro Preto (UFOP). Mestra em Educação pelo Programa de Pós-graduação em Educação da UFOP.

Jairo Antônio da Paixão é Professor do Curso de Licenciatura da Universidade Federal de Viçosa (UFV). Coordenador do Grupo de Pesquisa e Estudos Pedagógicos em Educação Física (GEPEF). Docente do Programa de Pós-Graduação em Educação (PPGE/UFV).

Recebido em outubro de 2017.

Aprovado em fevereiro de 2018. 